\title{
MMP-8 C-799 T, Lys460Thr, and Lys87Glu variants are not related to risk of cancer
}

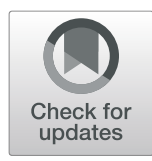

\author{
Li-Feng Zhang ${ }^{1,2 \dagger}$, Li-Jie Zhu ${ }^{3 \dagger}$, Wei Zhang ${ }^{4 \dagger}$, Wei Yuan ${ }^{5 \dagger}$, Ning-Hong Song ${ }^{1 *}$ (D) Li Zuo ${ }^{2^{*}}$, Yuan-Yuan Mi ${ }^{3^{*}}$, \\ Zeng-Jun Wang ${ }^{1}$ and Wei Zhang ${ }^{1}$
}

\begin{abstract}
Background: Several studies have focused on the relationship between MMP-8 variants and cancer risk, but they have been unsuccessful in drawing reliable conclusions.

Methods: We employed odds ratio (OR) together with 95\% confidence interval (Cl) to assess the correlation between MMP-8 C-799 T, Lys460Thr, and Lys87Glu polymorphisms and cancer risk. We further employed in silico tools to evaluate the effect of MMP-8 expression on cancer susceptibility and overall survival time.

Results: A total of 8140 patients with malignant carcinoma and 10,529 healthy individuals (control) were enrolled. Overall, the analysis showed that the relationship between three MMP-8 variants and cancer susceptibility was not significant (allelic contrast, C-799 T: OR $=0.98,95 \% \mathrm{Cl}=0.92-1.04, P_{\text {heterogeneity }}=0.068$; Lys460Thr: $\mathrm{OR}=0.94$, $95 \% \mathrm{Cl}=0.67-1.32, P_{\text {heterogeneity }}=0.905 ;$ Lys87Glu: $\left.\mathrm{OR}=1.05,95 \% \mathrm{Cl}=0.93-1.18, P_{\text {heterogeneity }}=0.968\right)$. Similar results were observed in subgroup analysis by ethnicity, cancer type, and source of control. In silico analysis indicated that MMP-8 expression was elevated in bladder cancer tissue compared to that in the control. However, both the higher and lower MMP-8 expression groups did not show an impact on the overall survival time of the patients.
\end{abstract}

Conclusions: MMP-8 C-799T, Lys460Thr, and Lys87Glu variants are not participant with the susceptibility of cancer.

Keywords: MMP-8, Variant, Cancer, Analysis

\section{Background}

It is well-known that the development of carcinoma is complex and has not been completely clarified. Hereditary material and genetic polymorphisms may probably have an impact on cancer susceptibility and play a crucial role in the tumorigenesis of numerous carcinomas [1-4]. Previous studies have shown evidence that the genetic aspects measured by single nucleotide polymorphisms (SNPs) might be associated

\footnotetext{
* Correspondence: songninghong@tom.com; jiaomin0324@126.com; miniao1984@163.com

'Li-Feng Zhang, Li-Jie Zhu, Wei Zhang and Wei Yuan contributed equally to this work.

'Department of Urology, The First Affiliated Hospital of Nanjing Medical University, Nanjing, China

2Department of Urology, The Affiliated Changzhou No.2 People's Hospital of Nanjing Medical University, Changzhou 213003, Jiangsu Province, China ${ }^{3}$ Department of Urology, Affiliated Hospital of Jiangnan University, Wuxi 214000, China

Full list of author information is available at the end of the article
}

with cancer susceptibility [5-8]. Matrix metalloproteinases (MMPs) belong to a family of endopeptidases that can degrade various extracellular matrix proteins and treat numerous extracellular matrix (ECM) components $[9,10]$. Accumulated evidence has indicated that MMPs may have a critical role in cell inflammation, migration and carcinogenesis [11-13]. Increased levels of MMPs have been observed in the specimens of a number of cancer subjects, such as urinary bladder cancer, lung cancer, breast cancer, and malignant melanoma [14]. Among the MMPs, MMP8 is a collagen-cleaving enzyme present in connective tissue. The MMP8 is not only produced by neutrophils but also synthesized by a series of malignant tumor cells $[15,16]$. High level of MMP8 was reported in the fluid of ovarian cancer compared to control tissue [17].

Previous studies have showed evidence that genetic mutations and variants can predispose for malignant

(c) The Author(s). 2019 Open Access This article is distributed under the terms of the Creative Commons Attribution 4.0 International License (http://creativecommons.org/licenses/by/4.0/), which permits unrestricted use, distribution, and reproduction in any medium, provided you give appropriate credit to the original author(s) and the source, provide a link to the Creative Commons license, and indicate if changes were made. The Creative Commons Public Domain Dedication waiver (http://creativecommons.org/publicdomain/zero/1.0/) applies to the data made available in this article, unless otherwise stated. 
tumors $[18,19]$. Human $M M P-8$ gene comprises twelve exons and is located on chromosome 11q22.3 [20]. Polymorphisms of $M M P 8$ can lead to gene dysfunction, microenvironment disorder and potential carcinogenesis. It has been reported that several single nucleotide polymorphisms (SNPs) of MMP8 can influence the gene expression by altering its promoter activity. In addition, the $\mathrm{T}$ allele of MMP8 C-799 $\mathrm{T}$ variant was reported to be related to breast carcinoma susceptibility and lymph node metastasis among Asian and Caucasian population [21]. Furthermore, electrophoresis mobility shift assays have demonstrated that the difference in nucleoprotein binding to oligodeoxynucleotides was correlated with MMP8 C-799 T variation [22]. However, Wieczorek et al. indicated that genetic variation in MMP8 C-799 T was not associated with urinary bladder cancer susceptibility in Caucasian descendants [23].

A number of studies have evaluated the association of MMP8 genetic variants including C-799 T (rs11225395 C/T), Lys460Thr (rs35866072 A/C), and Lys87Glu (rs1940475 G/A) SNPs, with cancer risk. Research on these MMP8 variations have been carried out in numerous countries, such as USA, Mexico, Poland, India, Korea, and China [23-35]. Nevertheless, there were controversial results on the relationship between MMP8 variations and various cancers among different case control studies. Therefore, we conducted a comprehensive analysis based on accumulated data of all eligible studies to investigate the impact of MMP-8 C-799 T, Lys460Thr, and Lys87Glu polymorphisms on overall cancer susceptibility.

\section{Methods}

\section{Database searching and screening process}

Comprehensive literature search on PubMed, Web of Science, EMBASE (Excerpta Medica Database), and SinoMed (China Wanfang Databases) was carried out to identify all eligible case-control studies, prior to June 2019. Valid keyword search strings are as follows: (MMP-8 OR matrix metalloproteinases 8) AND (polymorphism OR variant OR mutation OR SNP) AND (carcinoma OR tumor OR malignancy OR cancer). Furthermore, we independently retrieved the references in the identified articles to screen other available studies, with no language restriction. For studies with overlapping data, we selected the most recently published ones.

\section{Inclusion and exclusion criteria}

Eligible studies should meet the following inclusion criteria: (a) evaluate the relationship between $M M P-8 \mathrm{C}$ $799 \mathrm{~T}$, Lys460Thr, and Lys87Glu polymorphisms and cancer risk; (b) case-control study; and (c) contain available data on the frequency of genotypes. We independently excluded unpublished case reports, letters, reviews, meta-analyses, or missing genotype data for C-799 T, Lys460Thr, and Lys87Glu variants. We also excluded the studies that focused only on the case population.

\section{Data extraction and quality assessment}

Two authors (LFZ and YYM) independently completed the data extraction based on the selection criteria. Any potential disagreement was discussed comprehensively to obtain a final consensus. The main features of included studies are summarized, which includes: first author's name, year of publication, origin and race, type of cancer, age range, total number of participants, genotyping assay of $M M P-8$ C-799 T, Lys460Thr, and Lys87Glu variants in cases and controls, $P$-value of Hardy-Weinberg equilibrium (HWE) in controls. The quality score of the eligible studies was evaluated by Newcastle-Ottawa Scale (NOS). The research was regarded as high-quality if it acquired six or more stars.

\section{Statistical analysis}

We calculated the OR with $95 \% \mathrm{CI}$ to investigate the strength of the relationship between $M M P-8$ C-799 T, Lys460Thr, and Lys87Glu polymorphisms and cancer susceptibility. A total of five genetic models were adopted: allelic contrast (M-allele vs. W-allele, for C-799 T, T vs. C; for Lys460Thr, C vs. A; for Lys87Glu, A vs. G), homozygote model (MM vs. WW, for C-799 T, TT vs. CC; for Lys460Thr, CC vs. AA; for Lys87Glu, AA vs. GG), heterozygote model (MW vs. WW, for C-799 T, TC vs. CC; for Lys460Thr, CA vs. AA; for Lys87Glu, AG vs. GG), dominant comparison (MM + MW vs. WW, for C-799 T, TT + TC vs. CC; for Lys460Thr, CC+ CA vs. AA; for Lys87Glu, $\mathrm{AA}+\mathrm{AG}$ vs. GG), recessive comparison (MM vs. $\mathrm{MW}+$ WW, for C-799 T, TT vs. TC + CC; for Lys460Thr, CC vs. CA + AA; for Lys87Glu, AA vs. AG + GG). Q-test was utilized to estimate the heterogeneity among enrolled researches. If the heterogeneity was absent $(P>0.05)$, the fixed-effects model was employed [36]; alternatively, the random-effects model was performed [37]. Stratified analyses were carried out according to race (Asian, Caucasian, and Latin), type of cancer (bladder cancer and other cancers), and source of control. Hardy-Weinberg equilibrium (HWE) in the control group was calculated using a Chi-squared test. Begg's funnel plot and the Egger's test were both performed to measure the possible publication bias. $P$ values of Begg's and Egger's test more than 0.05 indicated the absence of publication bias. The STATA software (Version 11.0, Stata Corporation, College Station, TX, USA) was adopted for all the above analyses. 


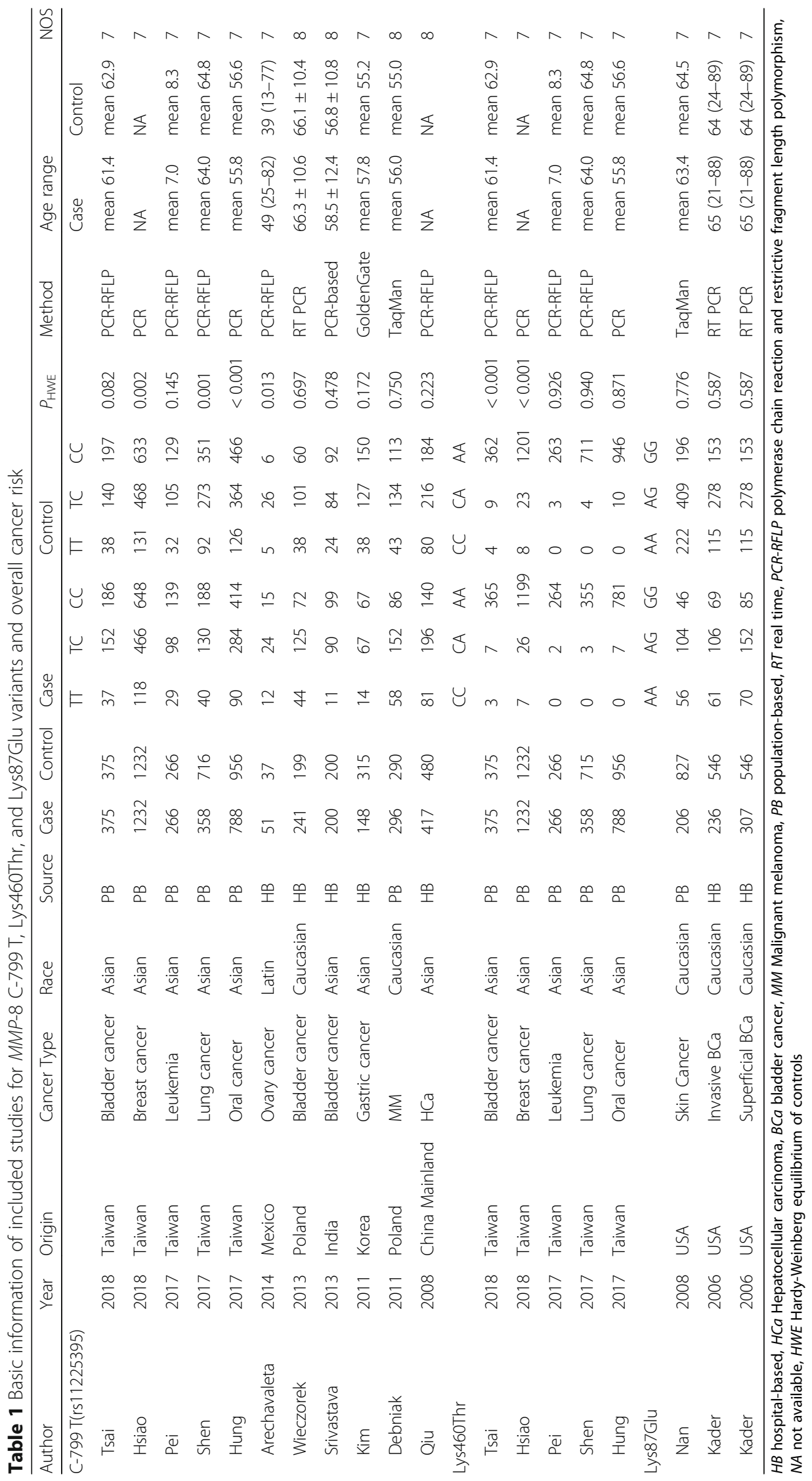


In silico analysis of MMP-8

To further investigate whether the expression of $M M P-8$ has an impact on tumorigenesis, we employed the online TCGA database to evaluate the $M M P-8$ expression in bladder cancer tissue and control counterparts. The effect of the expression of $M M P-8$ on bladder cancer patients' overall survival time was also assessed. Furthermore, we adopted bioinformatics tools, like Polyphen-2 (http://genetics.bwh.harvard. edu/pph2/), to predict the role of $M M P-8$ SNPs at the protein level.

\section{Results}

\section{Characteristics of included studies}

Main characteristics of the eligible articles as well as the genotyping assay results of $M M P-8$ C-799 T, Lys460Thr, and Lys87Glu variants have been summarized in Table 1. A total of 13 publications containing 19 case-control studies for the $M M P-8$ polymorphisms in compliance with the inclusion criteria were finally identified in the present analysis. All eligible studies had NOS score more than 6. There were 4372 cancer patients and 5066 control participants for the analysis of $M M P-8 \mathrm{C}-799 \mathrm{~T}$ variant. Five articles were acquired for assessing the association of $M M P-8$ Lys460Thr variant on cancer susceptibility, including 3019 cases and 3544 control subjects. There were 749 cases and 1919 controls on the Lys87Glu polymorphism. The MAFs (minor allele frequencies) of $M M P-8 \quad \mathrm{C}-799 \mathrm{~T}$ variants were shown in Fig. 1: African, 0.185; East Asian, 0.423; European, 0.411; South Asian, 0.350; and American, 0.440. For MMP-8 Lys460Thr polymorphism: African, 0.222; East Asian, 0.009; European, 0.044; South Asian, 0.060; and American, 0.060. The MAFs for Lys87Glu variant were: African, 0.290; East Asian, 0.432; European, 0.453; South Asian, 0.400; and American, 0.480. In stratified analysis by race, 13 case-control studies were conducted on Asian descendants; five were based on the Caucasian population and one was based on Latin descendants. In stratified analysis by cancer type, four studies concerned bladder cancer. The rest were focused on other cancers, such as lung cancer, hepatocellular carcinoma, malignant melanoma, oral cancer, ovary cancer, and gastric cancer. In stratified analysis by the source of control, 12 studies were population-based controls, and the rest seven were hospital-based studies.

\section{Quantitative synthesis}

Summarized results and details of the present analyses for the three $M M P-8$ polymorphisms and cancer risk are provided in Table 2 . Overall analysis indicated that the relationship between the three $M M P-8$ variants and cancer susceptibility was not significant. The $M M P-8$ $\mathrm{C}-799 \mathrm{~T}$ variant is not associated with the susceptibility of cancer under all genetic models (allele contrast: $\mathrm{OR}=0.98,95 \% \mathrm{CI}=0.92-1.04, P_{\text {heterogeneity }}=0.068, P=$ 0.429 ; TT vs. $\mathrm{CC}: \mathrm{OR}=0.94,95 \% \mathrm{CI}=0.82-1.07, P_{\text {heter- }}$ ogeneity $=0.097, \quad P=0.362$; heterozygote comparison: $\mathrm{OR}=1.00,95 \% \mathrm{CI}=0.92-1.09, P_{\text {heterogeneity }}=0.193, P=$ 0.992; TT + TC vs. CC: $\mathrm{OR}=0.98,95 \% \mathrm{CI}=0.90-1.07$, $P_{\text {heterogeneity }}=0.086, P=0.666$; recessive model: $\mathrm{OR}=$ $0.94, \quad 95 \% \quad \mathrm{CI}=0.83-1.07, \quad P_{\text {heterogeneity }}=0.249, \quad P=$ $0.348)$. In subgroup analysis by cancer type, we also indicated no relationship between $M M P-8 \mathrm{C}-799 \mathrm{~T}$ variant and bladder cancer ( $\mathrm{T}$ vs. $\mathrm{C}$ : $\mathrm{OR}=0.97,95 \% \mathrm{CI}=$ $0.83-1.12, P=0.671$, Fig. 2 ; TT vs. CC: $\mathrm{OR}=0.85,95 \%$ $\mathrm{CI}=0.61-1.17, P=0.316 ; \mathrm{TC}$ vs. $\mathrm{CC}: \mathrm{OR}=1.08,95 \%$ $\mathrm{CI}=0.87-1.33, P=0.492 ; \mathrm{TT}+\mathrm{TC}$ vs. $\mathrm{CC}: \mathrm{OR}=1.02$, $95 \% \mathrm{CI}=0.84-1.25, P=0.813$; $\mathrm{TT}$ vs. $\mathrm{TC}+\mathrm{CC}: \mathrm{OR}=$ $0.83,95 \% \mathrm{CI}=0.61-1.12, P=0.219)$ or other cancers (T vs. $C:$ OR $=0.99,95 \% C I=0.89-1.11, P=0.898$; TT vs. $\mathrm{CC}$ : $\mathrm{OR}=0.96,95 \% \mathrm{CI}=0.83-1.11, P=0.578 ; \mathrm{TC}$
A

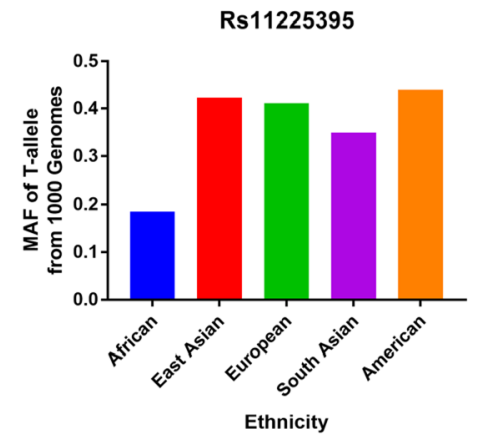

B

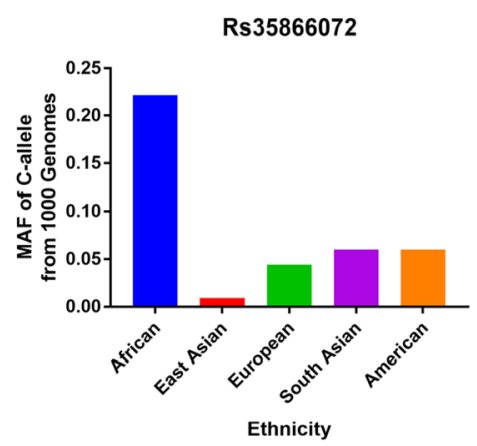

\section{C}

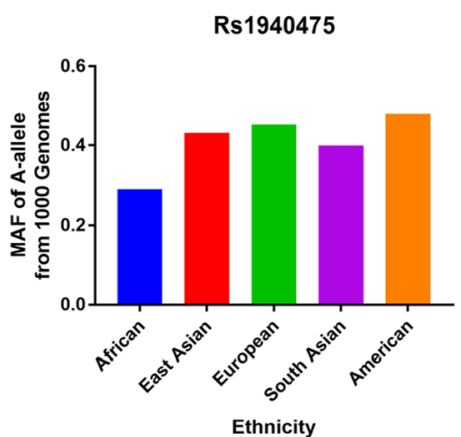

Fig. 1 Minor allele and major allele frequencies for MMP-8 C-799 T (a), Lys460Thr (b), and Lys87Glu (c) variants in controls stratified by ethnicity. Vertical line, allele frequency; Horizontal line, allele type 


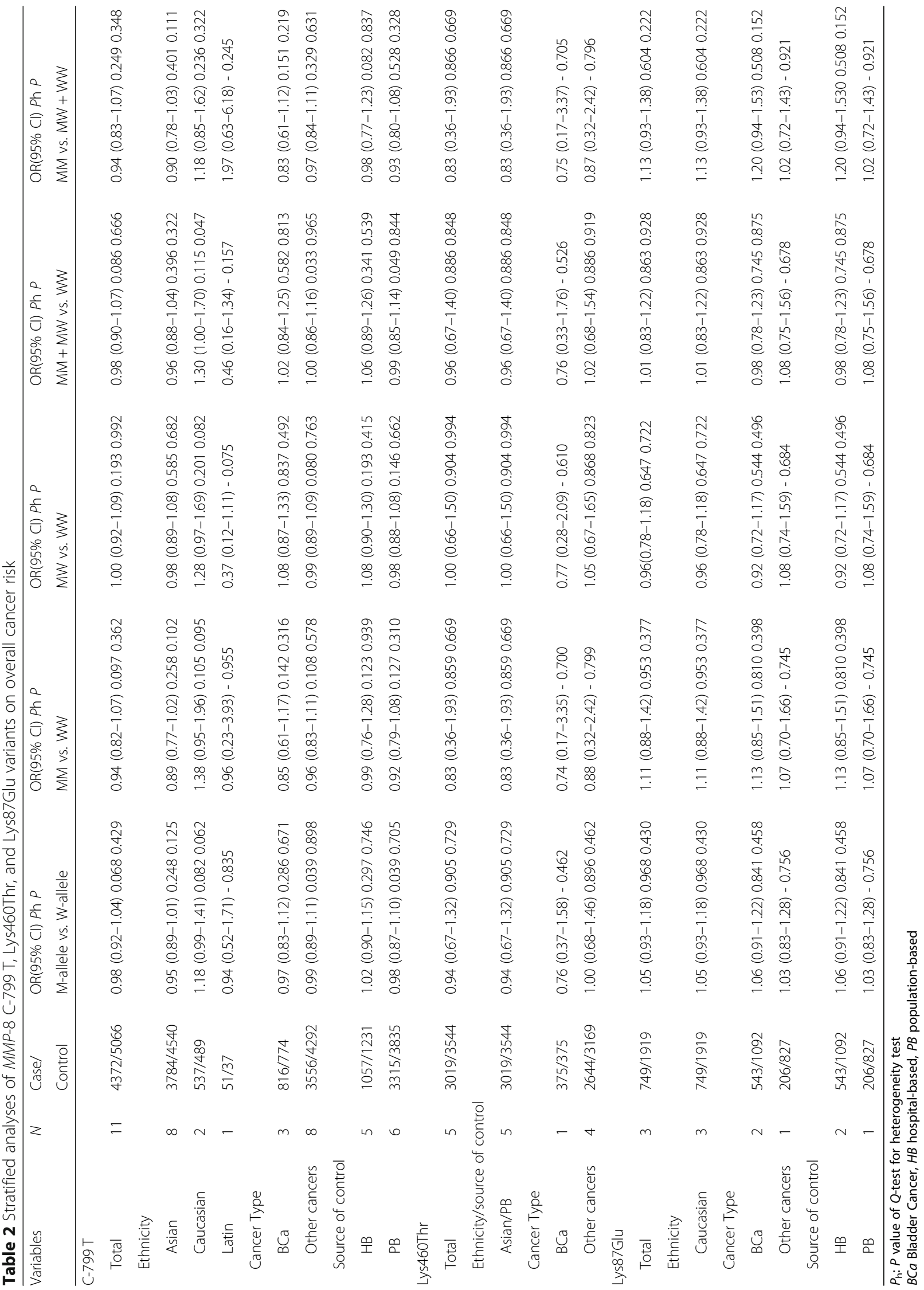




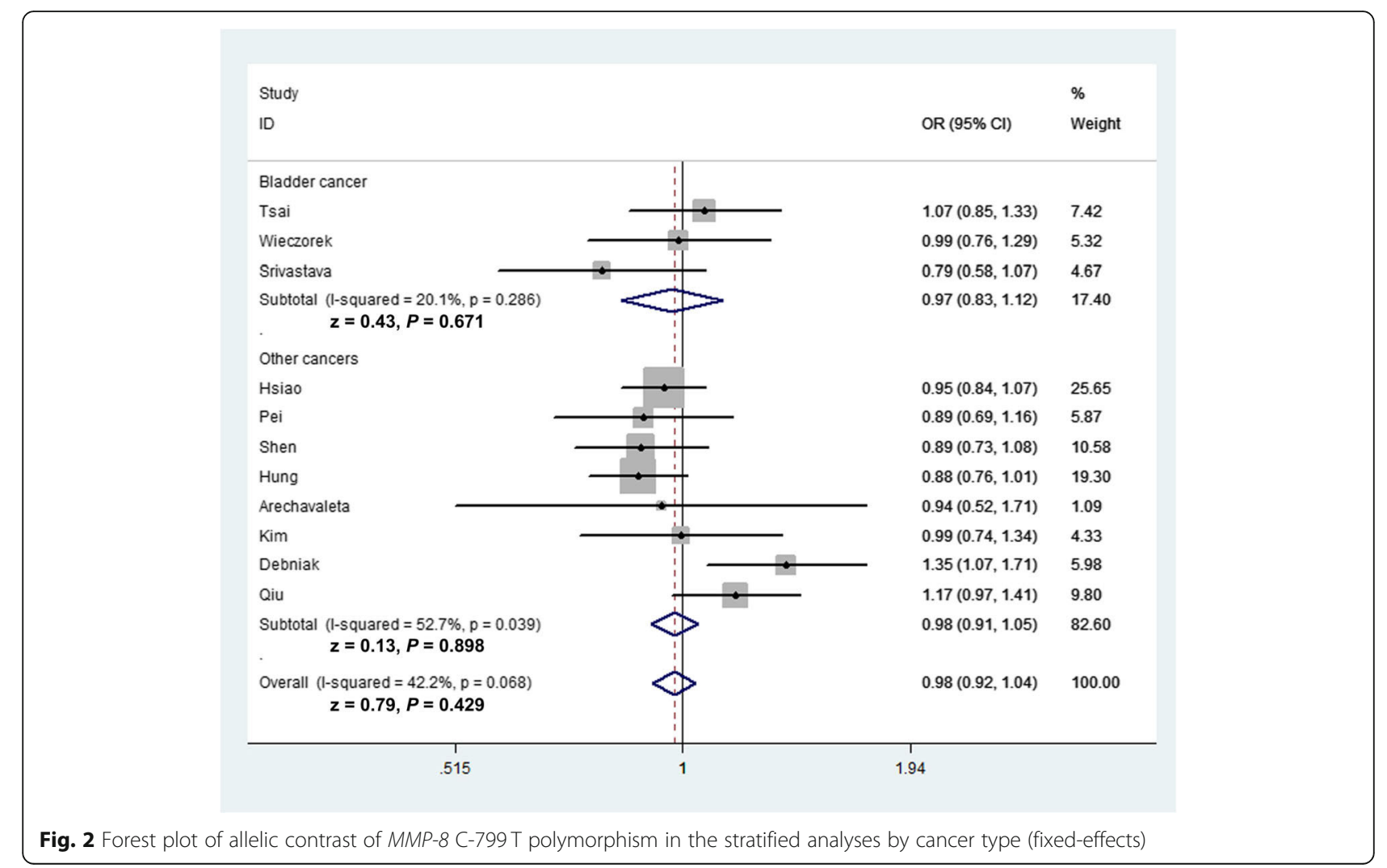

vs. $\mathrm{CC}$ : $\mathrm{OR}=0.99,95 \% \mathrm{CI}=0.89-1.09, P=0.763$; TT + TC vs. $\mathrm{CC}: \mathrm{OR}=1.00,95 \% \mathrm{CI}=0.86-1.16, P=0.965$; TT vs. $\mathrm{TC}+\mathrm{CC}: \mathrm{OR}=0.97,95 \% \mathrm{CI}=0.84-1.11, P=$ $0.631)$. In stratified analysis by race and source of control, no significant association between this polymorphism and cancer susceptibility was demonstrated (Fig. 3). For the MMP-8 Lys460Thr variant, we also indicated no major association of this variant on cancer risk ( $\mathrm{C}$ vs. $\mathrm{A}$ : $\mathrm{OR}=0.94,95 \% \mathrm{CI}=0.67-1.32, P_{\text {hetero- }}$ geneity $=0.905, P=0.729 ; \mathrm{CC}$ vs. $\mathrm{AA}: \mathrm{OR}=0.83,95 \%$ $\mathrm{CI}=0.36-1.93, P_{\text {heterogeneity }}=0.859, P=0.669 ; \mathrm{CA}$ vs. AA: $\quad \mathrm{OR}=1.00, \quad 95 \% \quad \mathrm{CI}=0.66-1.50, \quad P_{\text {heterogeneity }}=$ $0.904, P=0.994 ;$ TT + TC vs. $\mathrm{CC}: \mathrm{OR}=0.96,95 \% \mathrm{CI}=$ $0.67-1.40, \quad P_{\text {heterogeneity }}=0.886, \quad P=0.848 ; \quad$ recessive model: $\quad \mathrm{OR}=0.83,95 \% \quad \mathrm{CI}=0.36-1.93, \quad P_{\text {heterogeneity }}=$ $0.866, P=0.669$, Table 2$)$. In addition, similar results were revealed for the association between the MMP-8 Lys87Glu variant and cancer risk in allelic contrast $(\mathrm{OR}=1.05,95 \%$ $\mathrm{CI}=0.93-1.18, \quad P$ value for heterogeneity $=0.968, P=$ 0.430); homozygote model $(\mathrm{OR}=1.11$, 95\% CI $=0.88-$ $\left.1.42, P_{\text {heterogeneity }}=0.953, P=0.377\right)$; heterozygote comparison $(\mathrm{OR}=0.96,95 \% \mathrm{CI}=0.78-1.18, P$ value for heterogeneity $=0.647, P=0.722)$; dominant model $(\mathrm{OR}=$ $\left.1.01,95 \% \mathrm{CI}=0.83-1.22, P_{\text {heterogeneity }}=0.863, P=0.928\right)$, and recessive comparison $(\mathrm{OR}=1.13,95 \% \mathrm{CI}=0.93-1.38$, $\left.P_{\text {heterogeneity }}=0.604, P=0.222\right)$.

\section{In silico analysis of MMP-8}

Results from the TCGA database, containing 408 primary tumor and 19 normal samples, revealed that $M M P-8$ expression was elevated in bladder cancer tissue as compared to their control counterpart $(P<$ 0.01 , Fig. 4a). Furthermore, we investigated whether the $M M P-8$ expression had an effect on the overall survival time of bladder carcinoma participants. However, neither higher $M M P-8$ expression group nor lower expression group would have an impact on the patients' overall survival time $(P<0.05$, Fig. $4 \mathrm{~b}, \mathrm{c})$. In addition, we adopted the Polyphen-2 bioinformatics tool to analyze the associations between $M M P-8$ Lys460Thr (K460 T, rs35866072), and Lys87Glu (K87E, rs1940475) variants and protein damage. $\mathrm{Mu}-$ tations of these SNPs are predicted to be "BENIGN" with a score less than 0.05 , which indicated that neither Lys460Thr nor Lys87Glu SNP may probably damage the protein of MMP-8 (Fig. 5).

\section{Publication bias}

Both Egger's and Begg's funnel plot were employed for appraisal of the publication bias when evaluating MMP-8 C-799 T, Lys460Thr, and Lys87Glu variants. No evidence of publication bias was acquired for MMP-8 C-799 T polymorphism (T-allele vs. C-allele, 


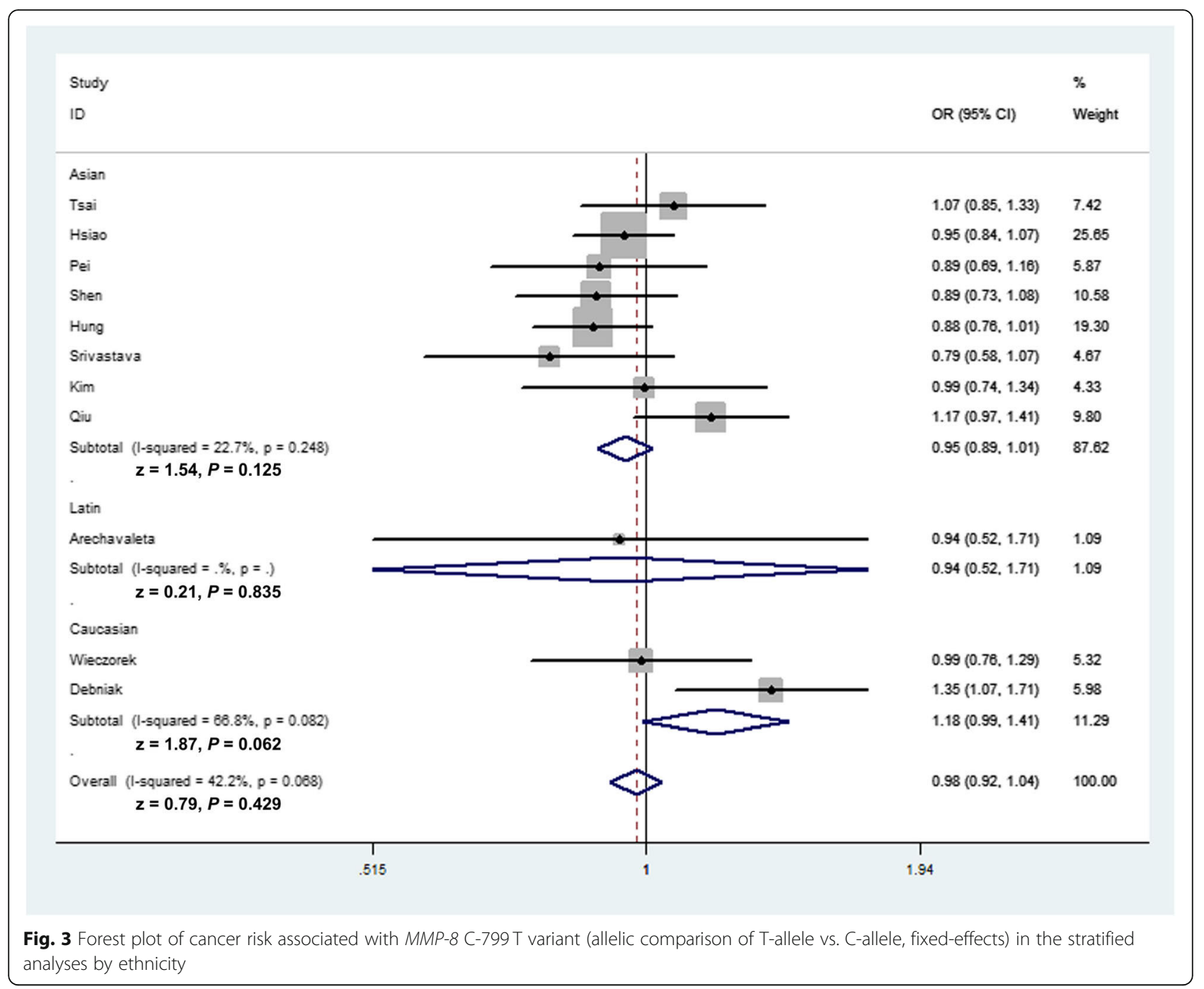

$\mathrm{t}=0.37, P=0.722 ; \mathrm{TT}$ versus $\mathrm{CC}, \mathrm{t}=0.26, P=0.801$; TC vs. $C C, \mathrm{t}=0.59, P=0.567 ; \mathrm{TT}+\mathrm{TC}$ versus $\mathrm{CC}$, $\mathrm{t}=0.62, P=0.552 ; \mathrm{TT}$ versus $\mathrm{TC}+\mathrm{CC}, \mathrm{t}=0.07, P=$ 0.945). For $M M P-8$ Lys460Thr variant: M-allele vs. $\mathrm{W}$-allele, $\mathrm{t}=-0.35, P=0.752 ; \mathrm{MW}$ vs. $\mathrm{WW}, \mathrm{t}=-0.71$, $P=0.527 ; \mathrm{MM}+\mathrm{MW}$ vs. $\mathrm{WW}, \mathrm{t}=-0.68, P=0.545$. For Lys87Glu variant: A vs. $\mathrm{G}, \mathrm{t}=0.38, P=0.771$; AA vs. GG, $\mathrm{t}<-0.01, P=0.998$; AG vs. GG, $\mathrm{t}=-0.04, P=$ $0.975 ;$ AA + AG vs. GG, $\mathrm{t}=-0.13, P=0.916$; AA vs. AG + $\mathrm{GG}, \mathrm{t}=1.71, P=0.338$. Outlines of the funnel plots were relatively symmetrical for overall cancer risk, implying no significant publication bias (Fig. 6).

\section{Discussion}

The MMP-8 serves as one of the most efficient collagenases and plays an essential role in carcinoma invasion and metastasis. Previous research demonstrated that advanced metastatic stage and further poor prognosis of carcinoma might be related to elevated expression of MMPs [38, 39]. Additionally, it was hypothesized that the regulatory effect of MMPs could be associated with variations in the $M M P$ genes. One group reported that the MMP8 C$799 \mathrm{~T}$ variant might be related to breast carcinoma susceptibility and lymph node metastasis in Asians and Caucasians [21]. However, another group investigated MMP8 variations among a representative Taiwanese breast carcinoma population and indicated no significant relationship between $M M P-8$ C-799 T, and Lys460Thr polymorphisms and cancer risk [34]. Therefore, it is reasonable to summarize all eligible data and draw more accurate conclusions to evaluate the contribution of $M M P-8$ polymorphisms to cancer risk. Furthermore, we employed the TCGA database and Polyphen2 bioinformatics tools to assess the role of $M M P-8$ expression on cancer risk and survival time.

In the present study, a total of 8140 patients with malignant carcinoma and 10,529 control participants 

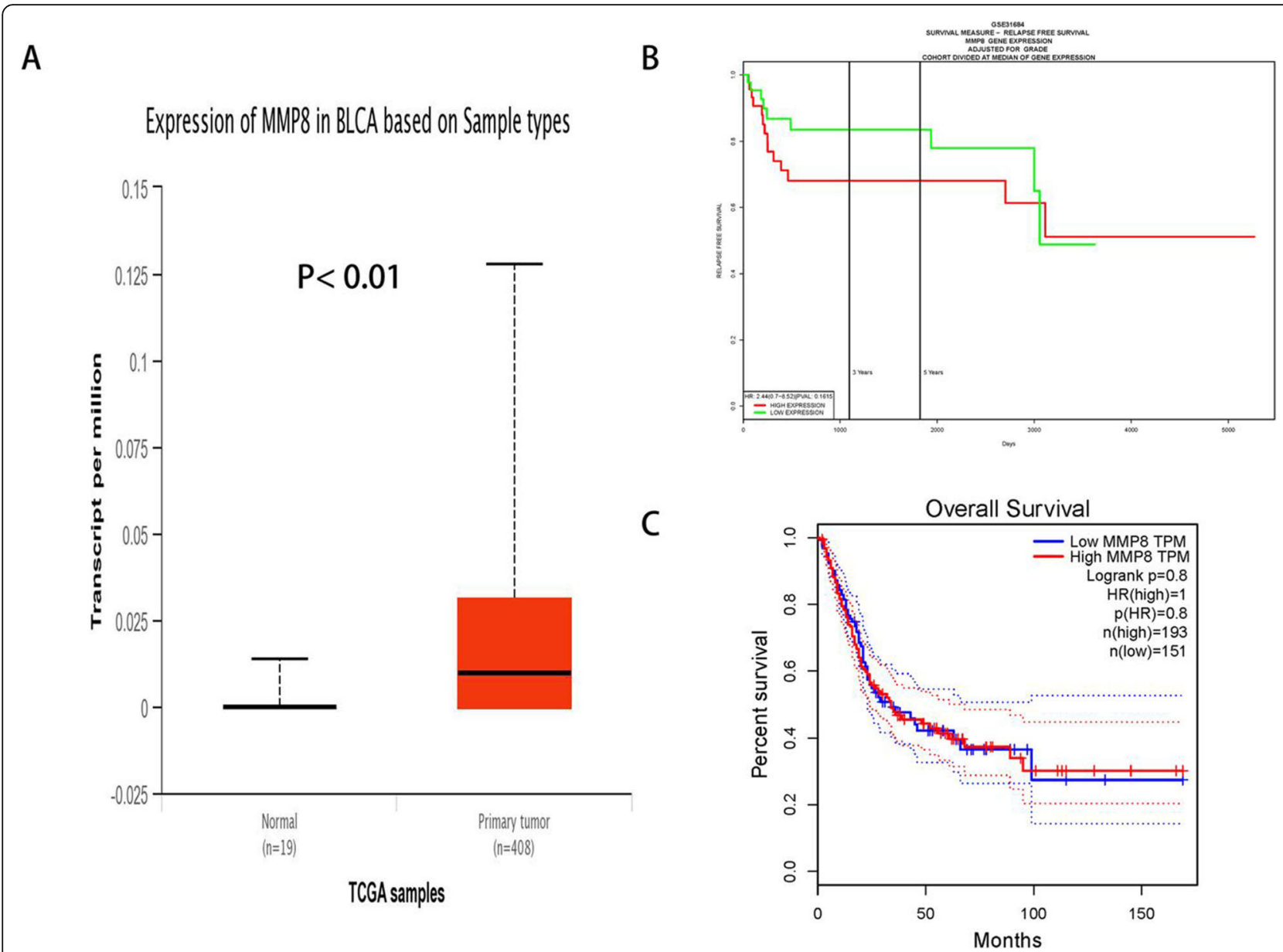

Fig. 4 In silico analysis of MMP-8 expression in bladder cancer (a). Association of the expression of MMP-8 and the overall survival (OS) time among bladder cancer participants (b, c)

were investigated. For MMP-8 C-799 T polymorphism, we observed no significant relationship with cancer risk $\quad\left(\mathrm{z}\right.$-value $=0.79, \quad P_{\text {heterogeneity }}=0.068, \quad P=0.429$, allelic contrast). Our finding was in agreement with the studies conducted by Hsiao et al., Huang et al., and Wieczorek et al [23, 31, 34]. In subgroup analysis by cancer type, this variation did not significantly confer susceptibility to urinary bladder cancer (zvalue $\left.=0.43, P_{\text {heterogeneity }}=0.286, P=0.671\right)$ and other cancers ( $\mathrm{z}$-value $\left.=0.13, P_{\text {heterogeneity }}=0.039, P=0.898\right)$. In stratified analysis by race, a similar result was indicated in Asian ( $\mathrm{z}$-value $=1.54, P_{\text {heterogeneity }}=0.248$, $P=0.125)$ and Caucasian descendants ( $\mathrm{z}$-value $=1.87$, $P_{\text {heterogeneity }}=0.082, P=0.062$ ). For $M M P-8$ Lys460Thr variant, no positive correlation was found in the overall analysis (z-value $=0.35, P_{\text {heterogeneity }}=0.905, P=$ 0.729). Similar results were indicated for Lys87Glu variant $\left(\mathrm{z}\right.$-value $\left.=0.79, P_{\text {heterogeneity }}=0.968, P=0.430\right)$. Results from in silico analysis showed that $M M P-8$ expression was elevated in bladder cancer tissue as compared to the control counterpart. However, both the higher and lower $M M P-8$ expression groups did not have an impact on the patients' overall survival time. Moreover, Polyphen-2 bioinformatics tool was also adopted to confirm the results of our present analysis. As the report for MMP-8 C-799 T (rs11225395) variation was not available, the association between Lys460Thr (K460 T, rs35866072), and Lys87Glu (K87E, rs1940475) variants and protein damaging was further investigated. Mutations of Lys460Thr and Lys87Glu were predicted to be "BENIGN" with a score less than 0.05, which indicated that these SNPs do not damage MMP- 8 protein, and are in agreement with the conclusions of the current analyses.

In addition, several limitations of the present study should be clarified. First of all, the number of enrolled studies for subgroup analysis remains insufficient, which exhibits fairly limited statistical power. Only five studies for MMP-8 Lys460Thr SNPs and three for Lys87Glu polymorphism were acquired based on the selection criteria. As regard to C-799 T variant, only two case-control studies were focused on 


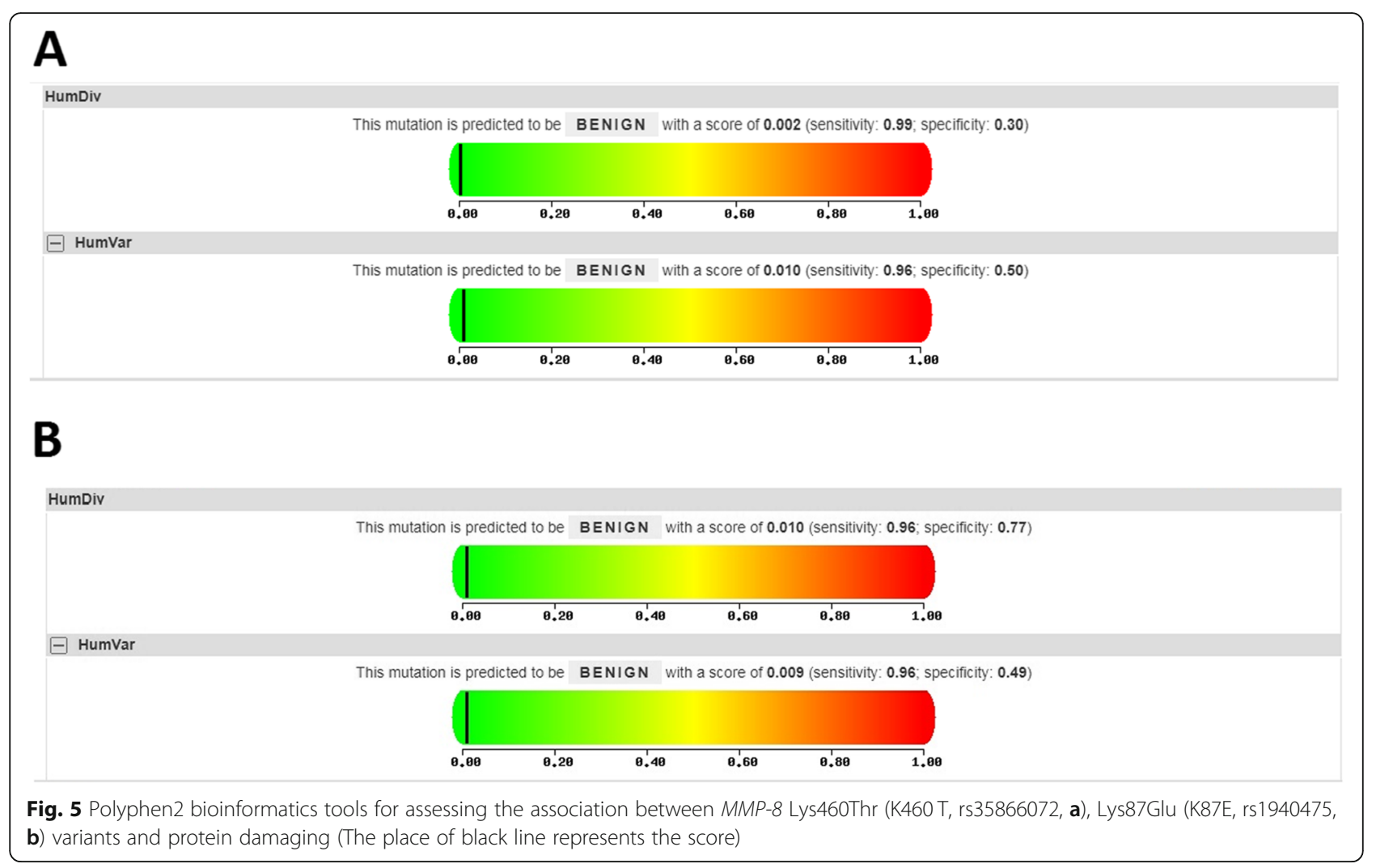

Caucasian population and one was based on Latin descendants. In addition, tumor stage and grade may potentially influence the results of the present analysis. We tried to further evaluate this effect in more details; however, raw data of eligible studies remains insufficient. More efficient investigations are still required to further strengthen the statistical power. Last but not least, $P$ value for HWE was less than 0.05 in five of the included articles [30, 31, 33-35], which might be exposed to unknown bias factors.

Despite these limitations, some key advantages should be acknowledged. First, all eligible case-control studies according to the selection criteria were obtained and the statistical efficiency was enhanced remarkably. Second, no obvious publication bias was indicated by
Egger's and Begg's funnel plot, which showed that the findings of the current analysis can be considered reliable. Additionally, NOS scores of the enrolled studies were more than 6 , which indicated a high methodological quality of each article.

\section{Conclusions}

Taken together, based on the currently published data, our study showed evidence that MMP-8 C-799 T, Lys460Thr, and Lys87Glu variants are not participant with the susceptibility of cancer. Further well-designed investigations are still warranted to confirm this conclusion in more detail.
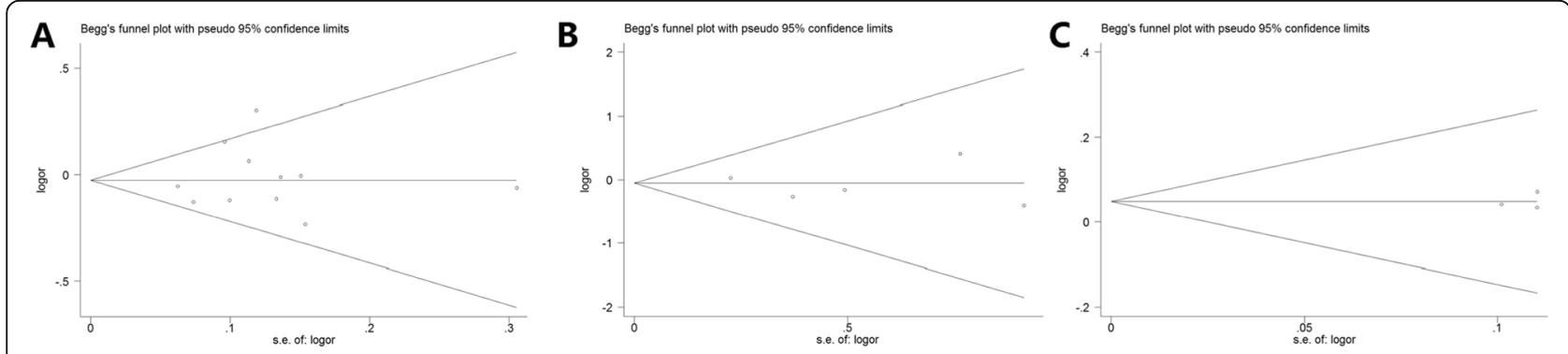

Fig. 6 Begg's funnel plot of standard error for investigating publication bias of MMP-8 C-799T (a), Lys460Thr (b), and Lys87Glu (c) variants under T-allele vs. C-allele genetic model 


\section{Abbreviations}

BCa: Bladder cancer; HB: Hospital-based; HCa: Hepatocellular carcinoma; HWE: Hardy-Weinberg equilibrium of controls; M-allele: Mutant allele; MM: Malignant melanoma; NA: Not available; NOS: Newcastle-Ottawa Scale; PB: Population-based; PCR-RFLP: Polymerase chain reaction and restrictive fragment length polymorphism; RT: Real time; W-allele: Wild-type allele

\section{Acknowledgements}

Not applicable.

\section{Authors' contributions}

NHS and LZ designed and conceived this study. WY, LJZ and WZ1 contributed to literature searching. LFZ and YYM were involved in data extraction. YYM, ZJW, and WZ2 analyzed the data. LFZ, WY and WZ1 wrote the manuscript. NHS and LZ revised the paper. All authors have approved the final edition of the manuscript. "WZ1" corresponding to Wei Zhang from Jiangsu Taizhou People's Hospital. "WZ2" corresponding to Wei Zhang from The First Affiliated Hospital of Nanjing Medical University.)

\section{Funding}

This work was supported by National Natural Science Foundation (Number: 81802576, 81902565, 81871151), Traditional Chinese Medicine Administration Fund of Jiangsu Province (No. YB201827), Changzhou High-Level Medical Talents Training (Project No. RC201620), Commission of Health and Family Planning of Wuxi (Project No.: J201803, Q201811, Z201712, J201810, Q201746, jzyx03), Jiangsu Province Medical Key Talent (ZDRCA2016009), Medical Young Talent of Wuxi City (QNRC043), Young Scientists Foundation of Changzhou No.2 People's Hospital (2019 K008), Jiangsu Post-Doc Scientific Research Grant (QT201710, QT201709), Sci \& Tech program of Changzhou (CJ20190100), Science and Technology Development of Wuxi (WX18IIAN024, CSE31N1605). The above funding bodies were financial support and were not involved in the study design, data analysis, writing of the manuscript or other aspect of this research.

\section{Availability of data and materials}

All the data generated in the present research is contained in this manuscript.

\section{Ethics approval and consent to participate}

Not applicable.

\section{Consent for publication}

Not applicable.

\section{Competing interests}

The authors declare that they have no competing interests.

\section{Author details}

'Department of Urology, The First Affiliated Hospital of Nanjing Medical University, Nanjing, China. ${ }^{2}$ Department of Urology, The Affiliated Changzhou No.2 People's Hospital of Nanjing Medical University, Changzhou 213003, Jiangsu Province, China. ${ }^{3}$ Department of Urology, Affiliated Hospital of Jiangnan University, Wuxi 214000, China. ${ }^{4}$ Department of Oncology, Taizhou People's Hospital, Taizhou 225300, Jiangsu, China. ${ }^{5}$ Department of Cardiology, Taizhou People's Hospital, Taizhou 225300, Jiangsu, China.

Received: 8 June 2019 Accepted: 6 September 2019

Published online: 21 October 2019

\section{References}

1. Yokota J, Shiraishi K, Kohno T. Genetic basis for susceptibility to lung cancer: recent progress and future directions. Adv Cancer Res. 2010;109:51-72.

2. Marshall AL, Christiani DC. Genetic susceptibility to lung cancer--light at the end of the tunnel? Carcinogenesis. 2013;34(3):487-502.

3. Kiyohara C, Yoshimasu K. Genetic polymorphisms in the nucleotide excision repair pathway and lung cancer risk: a meta-analysis. Int J Med Sci. 2007; 4(2):59-71.

4. Shao HB, Ren K, Gao SL, Zou JG, Mi YY, Zhang LF, et al. Human methionine synthase A2756G polymorphism increases susceptibility to prostate cancer. Aging (Albany NY). 2018;10(7):1776-88.
5. Ge J, Liu H, Qian D, Wang X, Moorman PG, Luo S, et al. Genetic variants of genes in the NER pathway associated with risk of breast cancer: a largescale analysis of 14 published GWAS datasets in the DRIVE study. Int J Cancer. 2019. https://doi.org/10.1002/ijc.32371 [Epub ahead of print].

6. Zhang LF, Ren KW, Zuo L, Zou JG, Song NH, Mi YY, et al. VEGF gene rs3025039C/T and rs833052C/A variants are associated with bladder cancer risk in Asian descendants. J Cell Biochem. 2019;120(6):10402-12.

7. Alekseeva IV, Davletgildeeva AT, Arkova OV, Kuznetsov NA, Fedorova OS. The impact of single-nucleotide polymorphisms of human apurinic/ apyrimidinic endonuclease 1 on specific DNA binding and catalysis. Biochimie. 2019;163:73-83.

8. Ding WH, Ren KW, Yue C, Zou JG, Zuo L, Zhang LF, et al. Association between three genetic variants in kallikrein 3 and prostate cancer risk. Biosci Rep. 2018;38(6):1-11.

9. Lekstan A, Lampe P, Lewin-Kowalik J, Olakowski M, Jablonska B, Labuzek K, et al. Concentrations and activities of metalloproteinases 2 and 9 and their inhibitors (TIMPS) in chronic pancreatitis and pancreatic adenocarcinoma. J Physiol Pharmacol. 2012;63(6):589-99.

10. Sternlicht MD, Werb Z. How matrix metalloproteinases regulate cell behavior. Annu Rev Cell Dev Biol. 2001;17:463-516.

11. Malemud CJ. Matrix metalloproteinases (MMPs) in health and disease: an overview. Front Biosci. 2006;11:1696-701.

12. Bourboulia D, Stetler-Stevenson WG. Matrix metalloproteinases (MMPs) and tissue inhibitors of metalloproteinases (TIMPs): positive and negative regulators in tumor cell adhesion. Semin Cancer Biol. 2010;20(3):161-8.

13. Zhang LF, Mi YY, Cao Q, Wang W, Qin C, Wei JF, et al. Update analysis of studies on the MMP-9 -1562 C>T polymorphism and cancer risk. Mol Biol Rep. 2012;39(4):3435-41.

14. Moses MA, Wiederschain D, Loughlin KR, Zurakowski D, Lamb CC, Freeman MR. Increased incidence of matrix metalloproteinases in urine of cancer patients. Cancer Res. 1998;58(7):1395-9.

15. Stadlmann S, Pollheimer J, Moser PL, Raggi A, Amberger A, Margreiter $R$, et al. Cytokine-regulated expression of collagenase-2 (MMP-8) is involved in the progression of ovarian cancer. Eur J Cancer. 2003:39(17):2499-505.

16. Sirniö P, Tuomisto A, Tervahartiala T, Sorsa T, Klintrup K, Karhu T, et al. Highserum MMP-8 levels are associated with decreased survival and systemic inflammation in colorectal cancer. Br J Cancer. 2018;119(2):213-9.

17. Stenman M, Paju A, Hanemaaijer R, Tervahartiala T, Leminen A, Stenman UH, et al. Collagenases (MMP-1, -8 and -13) and trypsinogen-2 in fluid from benign and malignant ovarian cysts. Tumour Biol. 2003;24(1):9-12.

18. Smith KR, Hanson HA, Mineau GP, Buys SS. Effects of BRCA1 and BRCA2 mutations on female fertility. Proc Biol Sci. 2012;279(1732):1389-95.

19. Voskarides K. Combination of 247 genome-wide association studies reveals high cancer risk as a result of evolutionary adaptation. Mol Biol Evol. 2018; 35(2):473-85

20. Pendás AM, Santamaría I, Alvarez MV, Pritchard M, López-Otín C. Fine physical mapping of the human matrix metalloproteinase genes clustered on chromosome 11q22.3. Genomics. 1996;37(2):266-8.

21. Decock J, Long JR, Laxton RC, Shu XO, Hodgkinson C, Hendrickx W, et al. Association of matrix metalloproteinase- 8 gene variation with breast cancer prognosis. Cancer Res. 2007;67(21):10214-21.

22. Wang H, Parry S, Macones G, Sammel MD, Ferrand PE, Kuivaniemi H, et al. Functionally significant SNP MMP8 promoter haplotypes and preterm premature rupture of membranes (PPROM). Hum Mol Genet. 2004;13(21): 2659-69.

23. Wieczorek E, Reszka E, Wasowicz W, Grzegorczyk A, Konecki T, Sosnowski M, et al. MMP7 and MMP8 genetic polymorphisms in bladder cancer patients. Cent Eur J Urol. 2014;66(4):405-10.

24. Kader AK, Shao L, Dinney CP, Schabath MB, Wang Y, Liu J, et al. Matrix metalloproteinase polymorphisms and bladder cancer risk. Cancer Res. 2006;66(24):11644-8.

25. Nan H, Niu T, Hunter DJ, Han J. Missense polymorphisms in matrix metalloproteinase genes and skin cancer risk. Cancer Epidemiol Biomark Prev. 2008;17(12):3551-7.

26. Qiu W, Zhou G, Zhai Y, Zhang X, Xie W, Zhang H, et al. No association of MMP-7, MMP-8, and MMP-21 polymorphisms with the risk of hepatocellular carcinoma in a Chinese population. Cancer Epidemiol Biomark Prev. 2008; 17(9):2514-8.

27. Dębniak T, Jakubowska A, Serrano-Fernández P, Kurzawski G, Cybulski C, Chauhan SR, et al. Association of MMP8 gene variation with an increased risk of malignant melanoma. Melanoma Res. 2011;21(5):464-8. 
28. Kim JH, Pyun JA, Lee KJ, Cho SW, Kwack KB. Study on association between single nucleotide polymorphisms of MMP7, MMP8, MMP9 genes and development of gastric cancer and lymph node metastasis. Korean J Gastroenterol. 2011;58(5):245-51.

29. Srivastava P, Kapoor R, Mittal RD. Association of single nucleotide polymorphisms in promoter of matrix metalloproteinase-2, 8 genes with bladder cancer risk in Northern India. Urol Oncol. 2013;31(2):247-54.

30. Arechavaleta-Velasco F, Cuevas-Antonio R, Dominguez-Lopez P, EstradaMoscoso I, Imani-Razavi FS, Zeferino-Toquero M, et al. Matrix metalloproteinase-8 promoter gene polymorphisms in Mexican women with ovarian cancer. Med Oncol. 2014;31(8):132.

31. Hung YW, Tsai CW, Wu CN, Shih LC, Chen YY, Liu YF, et al. The contribution of matrix metalloproteinase-8 promoter polymorphism to oral cancer susceptibility. In Vivo. 2017;31(4):585-90.

32. Pei JS, Chang WS, Hsu PC, Hung YW, Cheng SP, Tsai CW, et al. The contribution of MMP-8 promoter genotypes to childhood leukemia. In Vivo. 2017;31(6):1059-64.

33. Shen TC, Hsia TC, Chao CY, Chen WC, Chen CY, Chen WC, et al. The contribution of MMP-8 promoter polymorphisms in lung cancer. Anticancer Res. 2017;37(7):3563-7.

34. Hsiao CL, Liu LC, Shih TC, Chuang CL, Chen GL, Wang HC, et al. The association of matrix metalloproteinase-8 promoter genotypes in breast cancer. Anticancer Res. 2018;38(4):2181-5.

35. Tsai TH, Wang YM, Chang WS, Tsai CW, Wu HC, Hsu HM, et al. Association of Matrix Metalloproteinase-8 genotypes with the risk of bladder cancer. Anticancer Res. 2018;38(9):5159-64

36. Mantel N, Haenszel W. Statistical aspects of the analysis of data from retrospective studies of disease. J Natl Cancer Inst. 1959;22(4):719-48.

37. Barili F, Parolari A, Kappetein PA, Freemantle N. Statistical primer: heterogeneity, random- or fixed-effects model analyses? Interact Cardiovasc Thorac Surg. 2018;27(3):317-21.

38. Szarvas T, vom Dorp F, Ergün S, Rübben H. Matrix metalloproteinases and their clinical relevance in urinary bladder cancer. Nat Rev Urol. 2011;8(5): 241-54

39. O'Mara TA, Clements JA, Spurdle AB. The use of predictive or prognostic genetic biomarkers in endometrial and other hormone-related cancers: justification for extensive candidate gene single nucleotide polymorphism studies of the matrix metalloproteinase family and their inhibitors. Cancer Epidemiol Biomark Prev. 2009:18(9):2352-65.

\section{Publisher's Note}

Springer Nature remains neutral with regard to jurisdictional claims in published maps and institutional affiliations.

Ready to submit your research? Choose BMC and benefit from:

- fast, convenient online submission

- thorough peer review by experienced researchers in your field

- rapid publication on acceptance

- support for research data, including large and complex data types

- gold Open Access which fosters wider collaboration and increased citations

- maximum visibility for your research: over $100 \mathrm{M}$ website views per year

At BMC, research is always in progress.

Learn more biomedcentral.com/submissions 